\title{
EREBEA
}

Revista de Humanidades

y Ciencias Sociales

Núm. 8 (2018), pp. 23-43

ISSN: 0214-0691

\section{HERENCIA CULTURAL INTANGIBLE E INNOVACIÓN METACULTURAL: VILLALDEMIRO, VILLA DE LA ESCULTURA METÁLICA}

\author{
Ma Jesús Buxó Rey \\ Universidad de Barcelona
}

RESUMEN

2018 es el Año designado por la CE para celebrar el Patrimonio Cultural y promover iniciativas cívicas de cohesión y pertenencia. En este artículo se destaca un caso de revitalización cultural en Villaldemiro (Burgos), en el que la baja densidad de población contrasta con su resiliencia cultural activada por el diseño de innovaciones socioculturales. El registro etnográfico permite apreciar la activación de recursos simbólicos y a la vez mecanismos sociales de cooperación solidaria entre los vecinos del pueblo y la participación de promotores y amigos externos cuya conjunción vehicula el reconocimiento de la escultura metálica a través de encuentros, actos, concesión de premios y donaciones, a lo que se suman otras iniciativas como la biblioteca, el museo y la web villaldemirocultural.org. Denominada Villa de la Escultura Metálica, este pueblo constituye una comunidad creativa conectada con los fines CE: impulsar el encuentro del pasado con el futuro y diseñar proyectos sostenibles.

\section{Palabras Clave}

Innovación; metaculturalidad; resiliencia rural; solidaridad cultural; donación.

Fecha de recepción: 15 de sept. de 2018 Fecha de aceptación: 1 de oct. de 2018

\section{ABSTRACT}

2018 is the elected year by the European Community to celebrate Cultural Heritage and to promote initiatives and events to increase citizens' cohesion and cultural participation. In this paper, a case of cultural revitalization at Villaldemiro's village (Burgos) shows that its low demographic density contrasts with its capacity for cultural resiliency by promoting innovative designs of cultural and social activities. The ethnographic register allows observing the use of symbolic resources and the activation of cooperation and solidarity mechanisms among villagers, participating promoters and friends towards a common project: the recognition of metal sculpture artistry by way of acts, awards and donations as well as other initiatives such as a library, a museum and a web villaldemirocultural.org. Designated as Villa of Metal Sculpture, this village is a creative community connected to EC's purpose to impulse the meeting of past and future and the design of sustainable projects for future generations.

\section{KeYwords}

Innovation; metaculturality; rural resiliency; cultural solidarity; donation. 
2018 es el período elegido por la Comunidad Europea para declarar el Año Europeo del Patrimonio Cultural. El propósito de esta declaración es promover iniciativas y eventos que acerquen la herencia cultural tangible e intangible a los ciudadanos europeos con el fin de impulsar una mayor participación, cohesión, pertenencia y un desarrollo económico sostenible en el espacio europeo común. En sus términos ${ }^{1}$ :

"fomentar el intercambio y la apreciación del rico patrimonio europeo y reforzar el sentimiento de pertenencia a un espacio europeo común. El patrimonio cultural da forma a nuestra vida cotidiana, nos rodea en pueblos y ciudades, paisajes naturales y sitios arqueológicos. Une a Europa a través de nuestra historia y valores comunes. También representa la riqueza y diversidad de nuestras tradiciones culturales. Nuestro patrimonio cultural compartido debe ser entendido, apreciado y celebrado. El patrimonio cultural une a las personas y contribuye a sociedades más cohesionadas. Es un valor educativo para nińos y jóvenes, crea crecimiento y empleo en ciudades y regiones, así como contribuye al desarrollo económico y social sostenibles, es fundamental para los intercambios de Europa con el resto del mundo."

Ahora bien, el aspecto que este artículo se propone resaltar, hace referencia al "sin embargo" del texto relativo al diseño de futuribles y la innovación:

"Sin embargo, el patrimonio cultural no es solo un legado del pasado. También nos ayuda a forjar el camino a seguir y diseñar nuestro futuro. En 2018 también se promoverán las formas inteligentes de preservar, gestionar y reutilizar el patrimonio de Europa." 
En este sentido, y como parte de la celebración de este Año del Patrimonio Cultural, el Directorio General de la Comisión Europea para la investigación y la innovación ha organizado una conferencia en Bruselas para activar el diálogo sobre la herencia cultural y la innovación con el horizonte puesto en el 2020. En este marco, es relevante enfocar iniciativas que iluminen esta propuesta de dialogo y que se puedan situar etnográficamente en pueblos, ciudades y regiones cuya capacidad de resiliencia cultural responde a situaciones de despoblación/ implosión migratoria, desarrollo de baja intensidad, indiferencia administrativa, y también al impacto irregular de las NT y la alfabetización digital.

En este artículo se destaca un caso de revitalización cultural en un pueblo de la región Odra-Pisuerga, Villaldemiro, por su capacidad para promover el uso y la gestión innovadoras de la herencia cultural. No sólo por mantener la arquitectura antigua renovando los edificios, construir nuevos espacios deportivos, celebrar las festividades tradicionales y preservar la cohesión intergeneracional de la comunidad, sino también por el impulso creativo e instrumental para diseñar nuevas actividades culturales, incluso metaculturales, y abrirse a iniciativas con grupos procedentes de otras poblaciones. Esta revitalización abarca una amplia síntesis de bienes intangibles relativos al simbolismo iniciático y la recreación de la comunidad imaginada, el diseño de proyectos innovadores entorno a la escultura metálica y la activación de una atmósfera de encuentros y actos de reconocimiento artístico, donación de obras y libros y su difusión virtual en red y, por último, la conjunción de cooperación y solidaridad entre vecinos del pueblo y actores de otros lugares, a nivel regional e internacional.

\section{ENTRE LA HERENCIA INTANGIBLE Y LOS FUTURIBLES METACULTURALES: LA REVITALIZACIÓN INNOVADORA}

Por definición, UNESCO $2001^{2}$ considera que la herencia cultural no termina con los monumentos y los objetos, ni queda reducida a convenciones y listados inamovibles. De ahí el interés por diferenciar el patrimonio tangible del intangible que hace referencia a la expresión activa de las artes, los rituales y los eventos festivos; esto es, las habilidades orales y técnicas en toda suerte de narrativas y objetos, sin olvidar los conocimientos y prácticas relativas a la naturaleza, el universo y la sociedad. Sin embargo, enfocar el patrimonio intangible obliga a reflexionar sobre su caracterización conceptual ya que, por una parte no es deslindable del bien tangible y, por otra, no siempre su uso y significación se ajusta a las dinámicas o aceleraciones metaculturales del mundo de hoy, en especial porque los cambios culturales no son relevantes per se, sino por su capacidad para circular y recrearse transculturalmente.

2 UNESCO, Intangible Heritage, 2003. Disponible en http://whww.unesco.org/culture/heritage/intangible/html_eng/index_en.shtml/. Consultado el 25/11/2018. 
Antropológicamente, la idea de metacultura asimila el sentido de estructura conceptual doble para analizar la cultura que genera y activa cultura, enfoque que supera la idea de habitus o inercia esencialista y pone en evidencia la confluencia de fusiones y reinvenciones mundializadas por la circulación de expresiones y estilos culturales. Al decir de Urban (2001) se requiere un modo de autoreflexividad con la que observar la aceleración del movimiento y la circulación de fenómenos culturales inmateriales y materiales simultáneamente. Precisamente por trascender límites geográficos, étnicos, de clase, de época, de género, entre otros, y por el carácter efímero derivado de diferentes diseminaciones repetitivas o cíclicas en el tiempo y el espacio, la recombinación de elementos y expresiones diversas hace que los productos resultantes adquieran una entidad a veces innovadora y otras con apariencia de novedad.

En este ámbito, el Directorio de la Comisión Europea para la Investigación y la Innovación, en cooperación con el Directorio General para la Educación y la Cultura, las Redes de Comunicación, Contenido y Tecnología, ha promovido este año un encuentro dedicado a la cuestión de la "Innovación y la Herencia Cultural" con el horizonte puesto en el 2020. Estas conferencias y sesiones se han dedicado a discutir las políticas y las subvenciones orientadas a la innovación sobre cuestiones tales como, la gestión comunitaria del paisaje cultural, la regeneración de la herencia cultural en ciudades del conocimiento, soluciones digitales en la rehabilitación de monumentos, la cooperación transnacional de museos y el desarrollo de audiencias a través de los museos virtuales. Esta iniciativa es un apoyo para impulsar nuevos estudios y, en especial, descubrir y observar experiencias de regeneración cultural en el amplio marco de las comunidades de Europa. Esto requiere refinar los conceptos y dilucidar la vinculación entre el concepto de innovación y los cambios culturales afectados por el pluralismo transcultural de las dinámicas mundializadoras y las nuevas tecnologías. Si en el encuentro de Bruselas, el término regeneración ha servido para referirse al potencial creativo de las ciudades inteligentes en promocionar el uso y la gestión innovadoras de la herencia cultural, en el caso que nos ocupa, más que regeneración o recuperación, el término que mejor se ajusta a la vinculación armoniosa entre patrimonio cultural, tangible e intangible, y la transacción innovadora, es el de revitalización. Un concepto propuesto por Wallace ${ }^{3}$ (1956) en el sentido de un esfuerzo deliberado, organizado y consciente por los miembros de una sociedad para construir estilos culturales más satisfactorios.

No es simplemente aculturación, ni la adopción de otras formas culturales, sino que la revitalización implica un impulso de la comunidad, o de sus líderes, por cambiarse a sí misma, salir de patrones repetitivos y recombinar variables culturales

3 A. Wallace, The Death and Rebirth of the Seneca. Nueva York: Knopf Doubleday Publishing Group, 1969. 
propias y ajenas con el fin de modificar sus condiciones y resolver sus necesidades. Son diversos los dinamizadores que orientan la revitalización, sea la religión o el sincretismo religioso, u otras vías como la literatura y el arte interculturales ${ }^{4}$, aunque siempre la finalidad es agitar las ideas, avivar el sentimiento de cohesión y cambiar las condiciones de desarrollo y reconocimiento intercultural. Sin ser semejantes las condiciones culturales que ejemplifican etnográficamente este concepto de partida -situaciones de choque intercultural, decadencia y perdida de la dignidad-, no obstante, el bloqueo por factores o impactos diversos despoblación, marginación comunicativa y poca atención gubernamental-, permiten referirse a la revitalización al orientar los fines de una comunidad hacia la innovación de formulas culturales y así solventar la renovación de sus estilos de vida. Esto implica realizar ajustes en las prácticas y actitudes en respuesta a los cambios sociales, restricciones ambientales y los avances científicos y tecnológicos en salud y otros, a lo cual se ańade el factor responsabilidad ya que las decisiones son reales en sus consecuencias y afectan la transmisión intergeneracional. Desde esta perspectiva no deja de haber dificultades conceptuales cuando se quiere entender la resiliencia y la revitalización en términos de la vieja idea de ruralidad al igual que definir la cultura y la identidad en singular, puesto que el mundo rural de hoy se caracteriza por constituir un modelo de comunidad entre comunidades cada vez más continuas y complejas.

Si bien antropológicamente siempre estuvo claro que el mundo rural no era una isla cultural sino una función del mundo urbano ${ }^{5}$, las tendencias defensivas derivadas de la mundialización, la homogeneización de los mercados, las redes comerciales, los medios de comunicación y la sociedad en red, siguen enmarcando a los pueblos en el ámbito estricto de la ruralidad, la dicotomía rural-urbano y el contraste tradición-modernidad, por no mencionar las descripciones de lugares románticamente aislados, o abandonados. De este enfoque el principal problema es la definición de la cultura en singular, un tratamiento esencialista que recurre a las ideas, los hechos y las cosas como si fueran realidades permanentes. De ahí se deriva un sentido clónico y rutinario del sistema cultural que de hecho sólo parece valer para reproducir, legitimar y establecer claras diferencias entre los de aquí y los otros. Repliegue cultural que no siempre sirve a las aspiraciones, necesidades e intereses de la comunidad si bien la rigidez y simplicidad de rasgos y contenidos

4 Cfr. Las obras de M. J. Buxó Rey, "Identidad de frontera: la resolución estética entre la virtualidad de la escritura y la costumización motora”, en T. Calvo Buezas (coord.): Hispanos en Estados Unidos, inmigrantes en España: ¿amenaza o nueva civilización? Madrid: Catarata, 2006, pp. 342-350; y "Revitalización y síntesis cultural en la narrativa chicana”, en M. J. Buxó y T. Calvo, (coords.): Culturas hispanas de los Estados Unidos de América. Madrid: Cultura Hispánica, 1990, pp. 467-476.

5 R. Redfield, The little Community and Peasant Society and Culture. Chicago: The University of Chicago Press, 1956. 
pueda nutrir los proyectos turísticos, los justificantes ideológicos e históricos y los discursos políticos electorales de todo signo. Así, un sentido equívoco e interesado de la tradición soslaya los pasados múltiples al igual que ignora el trasfondo imaginativo e inventivo de la comunidad como sistema de conocimiento capaz de ajustar y combinar valores, ideas y creencias cuando la contingencia de los procesos de cambio lo requiere. En definitiva, enfocar la cultura en singular induce al equivoco de pensar en una ciudadanía rural que vive sujeta a categorías fijas, cogida o atrapada por sus significados explícitos e implícitos, siguiendo rutinariamente el dictum cultural, lo cual no deja ver la realidad compleja de los pueblos que constituyen la Europa intercultural y transnacional de hoy, interpenetrada de estilos rurales, urbanos y glocales, y aún menos considerar a la ciudadanía como agente responsable de su memoria y olvidos selectivos, de sus aprendizaje y adopción de formulas culturales diversas así como de sus invenciones.

Asimismo, esto se refleja en la construcción de la identidad pues lejos de barajar unidades precisas y situaciones claramente definidas, hoy convive con la fluidez, la mutabilidad, la variabilidad de percepciones y experiencias culturales diversas e indiferenciadas acorde a las condiciones cambiantes, a la distribución de los recursos culturales y las influencias transculturales. De hecho, la frontera como noción mítica de la identidad, y mecanismo de seguridad nacional y comercial, deja paso a otra definición más interactiva y porosa respecto a la construcción de las identidades glocales. En concreto cuando se trata de grupos y asociaciones aterritoriales que se caracterizan por la movilidad: migrantes, refugiados, exilados, trabajadores temporales, internautas así como organizaciones financieras y laboratorios industriales, entre otros. Este paisaje de identidades, denominado Ethnoscapes por Appadurai ${ }^{6}$, hace referencia a grupos que no están territorializados, no ocupan el mismo espacio, no son homogéneos culturalmente y afectan a la economía y la política entre naciones de forma compleja y, a veces, poco conocida. Y esto no es simplemente multiculturalismo, sino como los individuos y las comunidades son capaces de imaginar y construir la diversidad más allá de toda singularidad. Según Rosaldo ${ }^{7}$, esta porosidad tiene muchas ventajas ya que, al romperse las divisorias e hibridizarse los estilos culturales, se liberan energías creativas.

Sin duda las condiciones cambiantes a gran escala exponen a personas, grupos y comunidades a toda suerte de ingredientes culturales, actitudes políticas, ideas religiosas, tiempos heterogéneos, apetencias estéticas, gustos culinarios, percepciones humorísticas, por mencionar algunos rasgos. Y esta exposición puede

6 A. Appadurai, "Global Ethnoscapes: Notes and Queries for a Transnational Anthropology", en R. G. Fox (coord.): Recapturing Anthropology. Santa Fe, NM: School of American Research Press, 1991.

7 R. Rosaldo, Culture and Truth: The remaking of Social Analysis. Boston: Beacon Press, 1989. 
acabar en una simple imposición consumista por mucho que se disfrace de libertad de elección pero también entrenar para distinguir necesidades, intereses y alternativas. En este caso, innovar requiere una actitud activa, negociadora de significados e influencias capaces de seleccionar aquellos datos y tendencias que mejor favorezcan el surgimiento de ideas y la generación de diseños donde plasmar expresiones y estilos cualitativamente diferentes.

Antropológicamente, el concepto de innovación ha sido desarrollado por Barnett ${ }^{8}$ para explicar los procesos, los incentivos, las condiciones y las consecuencias del cambio cultural. Este autor no pone tanto la atención en el producto, o en las prácticas, como en la configuración social donde se produce, el contexto, la calidad, la necesidad social y las limitaciones del entorno considerando, incluso, las variables inconmensurables que no se despliegan hasta que el comportamiento y/o el producto entran en acción. Por lo tanto, el acto innovador radica en cómo se despliegan las ideas para generar valores añadidos y reactivar las decisiones y actitudes, y, atendiendo al sentido metacultural de la innovación, el interés de los productos resultantes se centra en lo que son capaces de mover y hacer circular.

A partir de aquí, lo relevante no es sí ciertos objetos, prácticas y habilidades innovadoras son o no específicas a una cultura, sino que reciban el reconocimiento de la comunidad así como de los individuos y grupos que las crean, mantienen y transmiten. La innovación ha de servir a un tipo de cohesión social que conecte el pasado con el futuro y permita compartir el sentido responsable de pertenencia intercultural.

En Italia, se pueden observar situaciones de innovación de alta revitalización como es el caso de Favara, situada en un municipio del sur de Sicilia, a pocos kilómetros de Agrigento. En este pueblo se ha realizado un proyecto titulado Farm Cultural Park 9 que presenta una agenda muy ambiciosa: construir un mundo mejor impulsado por una comunidad empeñada en inventar nuevas formas de pensar, habitar y vivir. De ser un pueblo marcado por la construcción ilegal y la mafia a lo largo del siglo pasado, a partir del 2010 se ha convertido en un núcleo de innovación artística y cultural. La regeneración local se realiza a través de la transformación de zonas abandonadas y degradadas del núcleo urbano que se reconvierten en un centro cultural independiente, un punto de creación artística hoy día de gran atracción turística.

Inicialmente impulsado por la iniciativa privada de dos propietarios de la zona centro del pueblo, pronto se involucra la población local, tanto de jóvenes como mayores. La innovación transformadora ha supuesto rediseñar la arquitectura y las funciones de las edificios y espacios así como activar la participación de los ve-

8 H. G. Barnett, Innovation: The basis of Cultural Change. Nueva York: McGraw-Hill, 1953.

9 Farm cultural park di Favara, disponible en www.humancities.eu/casestudies/farm-cultural-park-favara/. Consultado el 25/11/2018. 
cinos del pueblo lo cual genera una suerte de museo difuso que permite al visitante disfrutar de una experiencia de comunidad abierta con exposiciones de artistas de procedencia diversa, actuaciones artísticas y musicales, cursos y presentación de libros, siempre amenizado con la guía e interacción atenta de los cordiales vecinos. Se trata así de un proyecto conjunto en el que colaboran patrocinadores, artistas y voluntarios locales, y externos a la comunidad, participando todos en la organización y el crecimiento de este proyecto a largo plazo y en continua evolución. Por el momento ya se ha convertido en un vivero para el arte y un modelo para la renovación de las zonas rurales.

Si bien hoy los casos de revitalización cultural tienden a manifestarse a través de iniciativas artísticas, lo interesante es que el proceso y los resultados de la innovación no se parecen entre sí, y no hay conocimiento ni contactos previos entre comunidades. Si en cambio es común la originalidad de los diseños y las acciones que se constituyen en la espontaneidad, la solidaridad y la donación. Y este es el caso singular de Villaldemiro cuya etnografía reciente refleja una trayectoria propia que pone en evidencia las múltiples posibilidades de conexión, recreación y desarrollo sostenible entre la herencia cultural y la innovación.

\section{Villaldemiro, Villa de la Escultura Metálica}

En la comarca del Odra-Pisuerga, a unos treinta kilómetros de Burgos, junto al río Sambol, rodeada de campos de cultivo y zonas de valle y páramo, se encuentra Villaldemiro. Un pueblo caracterizado por una baja densidad demográfica, 81 habitantes (INE 2018) que, a pesar de la proximidad con la ciudad, la residencia estacional de sus vecinos no queda reducida al modelo de pueblo en función de la ciudad. En eso contribuye la buena comunicación de la red viaria, carreteras locales y autovía, a la vez que la cohesión y participación vecinal por mantener su estilo de vida y la celebración de sus festividades -en mayo Santa Juliana y San Isidro y, el primer domingo de octubre, la fiesta grande en honor a la Virgen del Rosario- así como diversas iniciativas del Ayuntamiento para impulsar el mantenimiento y el desarrollo de la comunidad.

En los años 70 se realizan una serie de obras de abastecimiento, distribución y saneamiento de aguas, en los 90 se acomete la pavimentación de calles y se hacen reparaciones en la iglesia parroquial financiadas a medias con el Arzobispado de Burgos a partir de la venta de la casa y fincas del cura, y, en 1998 se construye un polideportivo. El cambio de siglo, y también la crisis, orienta la gestión del ayuntamiento a emprender proyectos acordes a la tendencia de hacer de la vida rural una vía sostenible en población, energía y turismo. Con este fin se promueven varias iniciativas, en 2006 la construcción de un centro de ocio-temático dedicado al lejano oeste, Río Loco, y en 2008 la instalación de un campo de placas solares. Tentativas de éxito relativo que hacen que la gestión del ayuntamiento se adhiera, en 2013 y 2015, a otras iniciativas sostenibles y conjuntas como el parque eólico 
"el Gallo" de 49,4 MW. de potencia, con 26 aerogeneradores Vestas de $1.900 \mathrm{~kW}$. de potencia unitaria, ubicados en su término municipal así como en Los Balbases y Villaquirán de los Infantes. En 2014 se construye un Centro Social adjunto al ayuntamiento y se acomete con renovado vigor el arreglo y mantenimiento de calles, plazoletas y esquinas ajardinadas, sin olvidar la reconstrucción privada de las viejas casonas y bodegas.

La vitalidad de Villaldemiro es notoria y desde 2015 su capacidad de innovación se incrementa al participar en nuevos proyectos culturales que permiten reactivar sus espacios e infraestructuras, en particular el Centro Social. Estos proyectos se orientan a promover el encuentro de intelectuales y artistas, exposiciones de arte y lecturas poéticas, la habilitación de una biblioteca y la elaboración de una web. villaldemirocultural.org donde se editan diferentes apartados relativos a la información actualizada del pueblo, la historia, las actividades culturales y, además, la visualización de un museo virtual de escultura metálica. Proyectos y actividades que ahora culminan con la construcción de un museo para exponer obras de arte, ubicar actos y realizar actividades artísticas y sociales. Y, en esta dinámica, el propio pueblo se convierte en un espacio abierto donde situar, en plazas y esquinas, obras de arte al aire libre.

El trasfondo etnográfico de estos proyectos contiene aspectos procesuales característicos de la revitalización cultural y, a la vez, ingredientes de metaculturalidad y reflexividad. Constituye así una formula original de innovación en clave de emprendimiento y solidaridad al promover la circulación armoniosa del patrimonio tangible e intangible local en conjunción con iniciativas de intelectuales y artistas, apoyadas con la donación de obras de arte, libros y dedicación.

Esta colaboración añade valores de reflexividad en cuanto que alguna de estas iniciativas contribuye no sólo a difundir mejor sino también a saber más sobre la historia del pueblo. Un reconocimiento del lugar que procede de activar la historia local en la web gracias a la aportación solidaria del historiador Rilova Pérez cuyo texto permite poblar de personajes y circunstancias el paisaje cultural que da origen a Villaldemiro; son referentes de su fundación un repoblador visigótico procedente de Cantabria, el Cartulario de Arlanza (1062) donde consta la denominación Villa de Eldelmiro, nombre gótico traducible como noble insigne, y son referentes de su relevancia constituir en origen lugar de realengo (ni señor ni monasterio) y, el hecho que, en 1221, el rey Fernando III encomienda al noble García Fernández de Villaldemiro, mayordomo mayor, la crianza de su hijo, el futuro Alfonso X el Sabio, quien reside sus años jóvenes en las propiedades de este noble familia que se extendían a lo largo y ancho de Villaldemiro y Celada del Camino. Y otros muchos detalles que nutren la historia de la iglesia, las circunstancias bélicas, incluso un poema de José Zorrilla y García de Quevedo situado en las soledades de Villaldemiro y fechado en 1850. Este poema cuenta un relato de amores y odios seculares entre las familias de unos jóvenes enamorados quienes, 
una vez resuelto el conflicto, pasean su felicidad por la pintoresca vega de Villaldemiro. Un fragmento de este Cuento de Amores describe así el pueblo...

"y entre otros muchos cerrillos

que el terreno desigualan,

hay tendido un pueblecito

que se esconde a las miradas,

mas cuyo fecundo seno

tesoros avaro guarda.

Su nombre es harto poético,

aunque no está en ningún mapa

ni se lee en ninguna historia:

Villaldemiro le llaman."

La pregunta es, entonces, cuáles son los enlaces culturales y humanos que orientan este proyecto, cómo surge la implicación solidaria de los grupos que participan, qué impulsa la combinación de imaginación e intelecto para activar la intuición, inspiración, asociación de ideas y los diseños innovadores y cómo se mueven las oportunidades e intereses para que estas iniciativas pasen a ser actividades y circulen en diferentes contexto de acción. En definitiva, cómo el conjunto de estas experiencias y colaboraciones culmina con una denominación tan específica de Villadelmiro como "Villa de la Escultura Metálica".

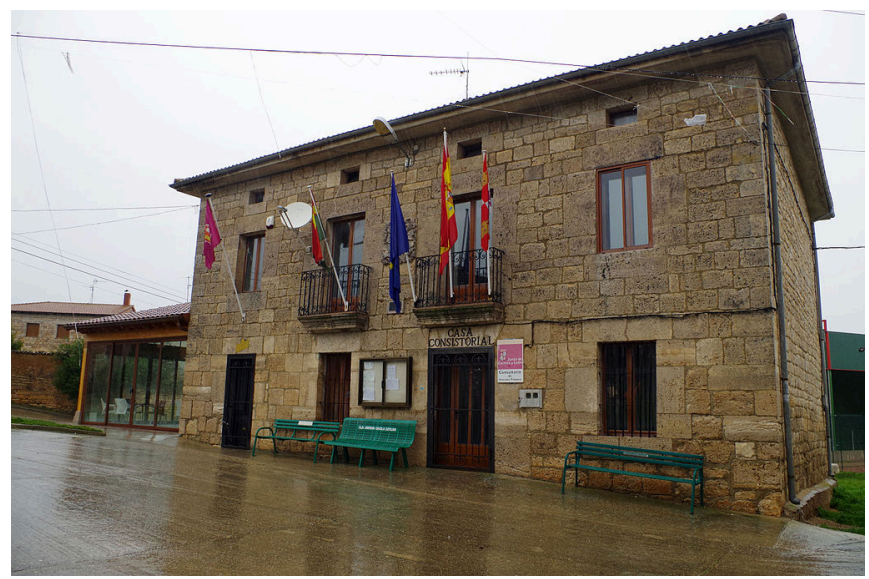

\section{Enlace ancestral}

Actualmente, más allá de referenciar las tradiciones en el ámbito estricto de la ruralidad y la autenticidad del pasado, la revitalización innovadora se activa en dominios y a través de variables y expresiones transculturales fluidas y en proceso constante de cambio a modo de multiprácticas rurales y urbanas. Se dan casos de 


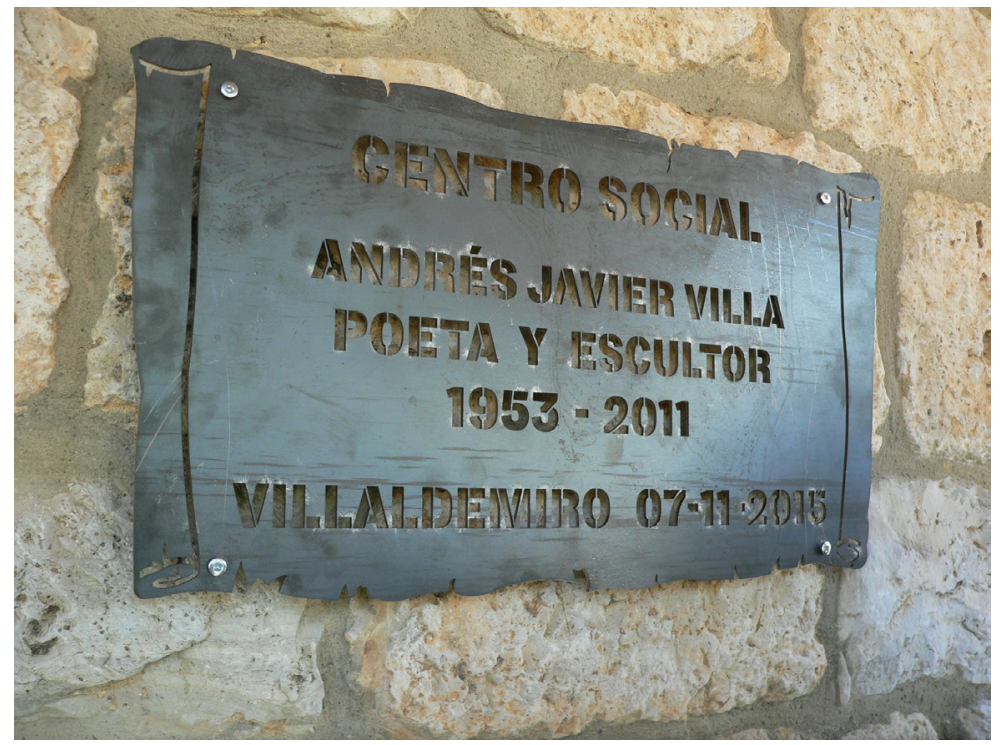

reinvención, a veces imitación de modelos como instaurar una fiesta o incorporar modas festivas, pero revitalizar requiere el diseño de nuevos rasgos culturales y la aplicación de recursos narrativos que den cuerpo, o aporten validez, a las propuestas y realizaciones.

En este sentido, no hay empresa cultural que desestime la eficacia narrativa y simbólica de la mítica y los rituales, y tampoco las técnicas de la analepsis y la prolepsis, incluso en los territorios más alejados de las humanidades como los avances tecnocientíficos cuando hacen uso de la retórica para describir o simular futuros probables. Desde la Antropología Cultural se ha hecho un gran esfuerzo por no confundir el pensamiento mítico con el primitivo y reducir la mitología a narrativas sobre los orígenes. Si nos detenemos en la revisión analítica de Detienne sobre La invención de la mitología (1985), este autor afirma que "procede de un mismo origen voluntario de la razón tanto en las sociedades arcaicas como en las formas más acusadas de la ciencia y la filosofía" ${ }^{10}$. Son así un buen ejemplo los fondos míticos que nutren conjeturas e hipótesis para construir de forma implícita el discurso científico tanto para definir la visión, o las ventajas, del proyecto investigador como en la difusión de resultados en revistas y medios de comunicación; sin olvidar la apoyatura de las narrativas utópicas y distópicas de la ciencia ficción, más apreciadas cuanto mayor o apocalíptica es la crítica a estos avances por su capacidad para alimentar actitudes ambiguas de aceptabilidad, temor o resistencia.

10 M. Detienne, La invención de la mitología. Madrid: Ediciones Península, 1985. 
Si se observa en retrospectiva lo que da origen a la denominación Villa de la Escultura Metálica hay que acudir a la conexión identitaria del presente con el pasado. Este vinculo se despliega en el relato del enlace ancestral entre dos personajes, un vecino del pueblo, Jesús Pérez Velasco (1903-1989) que emigró a Chile y su nieto, Andrés Javier Villa Pérez (1953-2011) a quien, precisamente por su obra poética y escultórica, el pueblo de Villaldemiro ha reconocido como vecino ilustre poniendo su nombre al Centro Social, el 7 de noviembre de 2015, así como al museo recientemente construido en una vieja casa y a inaugurar en noviembre de 2018.

El relato etnográfico se inicia en tiempo real, otońo de 2015, con la búsqueda del documento que acredita la filiación local del primero y por ende su vinculación con el segundo, pero a la vez intercala hechos que representan una vuelta súbita y acronológica al pasado, lo cual hace que tenga mucho de viaje iniciático y de activación de la comunidad imaginada. Así, la búsqueda contiene el tempo y los ingredientes de una aventura desde encontrar el pueblo hasta investigar en los archivos y descubrir el documento. Una vez localizados los pueblos natales probables, primero en el registro de Villaquirán de los Infantes en el que nada se encuentra, y ya entrada la tarde, se llega al ayuntamiento de Villaldemiro donde un sorprendido y colaborador alcalde contribuye a descubrir el acta de nacimiento fechada el 23 diciembre de 1903.

Sin obviar la relevancia del acuerdo posterior en el que se confirma el reconocimiento por parte de la comunidad, familiares y amigos, la voz etnográfica, que relata el hallazgo y contextualiza el trayecto, aporta en la descripción detalles que son extrapolables a los símbolos icónicos de un proceso ritual. Así, el acta es la personificación que asegura la ancestría del poeta-escultor, y esa misma noche, oscura y tormentosa, sigue un trayecto iniciático a través de una carretera estrecha bordeada de olmos que se doblan y crujen con el viento hasta abrirse, finalmente, a la luz del iluminado castillo de Olmillos de Sasamón. Transcurso que representa el recorrido vinculante a través de la tierra del pueblo, los abuelos y el poeta, un proceso ritual recurrente cuando se trata de unir la sensorialidad de la tierra con la pertenencia identitaria ${ }^{11}$.

Estos rasgos de in-corporación identitaria se perfilan en coincidencia con el fenómeno cultural relativo a la comunidad imaginada (Anderson, 1983). Vivir en una comunidad, sea por consideración de igualdad cultural o semblanza biogenética, une para emprender toda suerte de acciones: trabajar, defenderse y encontrar cauces de expresión festiva y artística, pero también para compartir el aspecto

11 Cfr. T. del Valle, Korrika: Rituales de la lengua en el espacio. Barcelona: Editorial Anthropos, 1988; M. J. Buxó Rey, "Delicadeza y extravagancia en las pasiones: paisajes de la emoción en las fronteras culturales de Nuevo México", en C. Lisón Tolosana (coord.): Antropología: Horizontes emotivos. Granada: Universidad de Granada, 2003, pp. 27-56. 
más íntimo de la comunidad imaginada, la inmortalidad de todos sus miembros, sean exilados o migrantes, representada en lo tangible por el cementerio y en lo intangible por el simbolismo de unir naturaleza y sociedad con el fin de proteger la vida, la fertilidad, la renovación y el renacimiento de la comunidad.

Propósitos que encajan con el mensaje vital del poeta, amante de la botánica y protector de los árboles, en especial de los olmos, en la conservación del bosque y la jardinería. Y a la vez hace referencia a su estética naturalista que se expresan en la talla de esculturas en madera de olmo y también en la expresión orgánica de esculturas de acero y hierro, en particular la serie Durvillaea Antarctica. Al decir del poeta-escultor A. J. Villa ${ }^{12}$ :

"no he buscado representar el aspecto inmediato de las algas, sino expresar la delicadeza del movimiento oscilante a base de líneas y curvas ondulantes compuestas de franjas de metal torsionado a la vez que tratado químicamente para adquirir los matices de luz que se reflejan en las algas al filtrarse el sol bajo el agua. Un biomorfismo que crece imaginativamente de lo vegetal a lo animal transfigurándose en animales míticos mediante espirales abiertas que guían el cuerpo de un toro de mar así como ondulaciones suaves entorno al círculo abierto de la cabeza de la medusa. Y de igual modo la serie de lunas constituye una expresión sensorial de la mujer, los ciclos y la sexualidad. Composiciones donde se conjugan las superficies planas y las circunferencias de hierro aportando el grosor de los cortes la sensación de peso y la fuerza de la materia -Mater- mientras los espacios abiertos y el encaje rugoso y fragmentario de las piezas producen el efecto de fusiones en el aire y su conversión en energía vital.”

Finalmente, en esta vinculación del presente con el pasado, es interesante constatar la percepción imaginativa de algunos vecinos de edad avanzada cuando identifican, en un cuadro de dibujos del poeta-escultor, el parecido de los rostros con parientes próximos y amigos, en su mayoría fallecidos, llenando así el tiempo vacío con narrativas de la intimidad: el lugar donde vivían y, entre vivencias y anécdotas, las relaciones de parentesco y amistad.

Ahora bien, una vez establecido el enlace invocador y sus mensajes, el relato etnográfico pone en evidencia la configuración social -personajes, actitudes, propuestas y decisiones- así como la evolución de las prácticas en actos y actividades según las oportunidades, la ideación colaborativa y la solidaridad; esto es, el motor humano y social que mueve los proyectos y los lleva a la acción.

12 A. J. Villa, Poemas Inéditos, 1953-2011. Madrid: Editorial Devenir, 2018. 


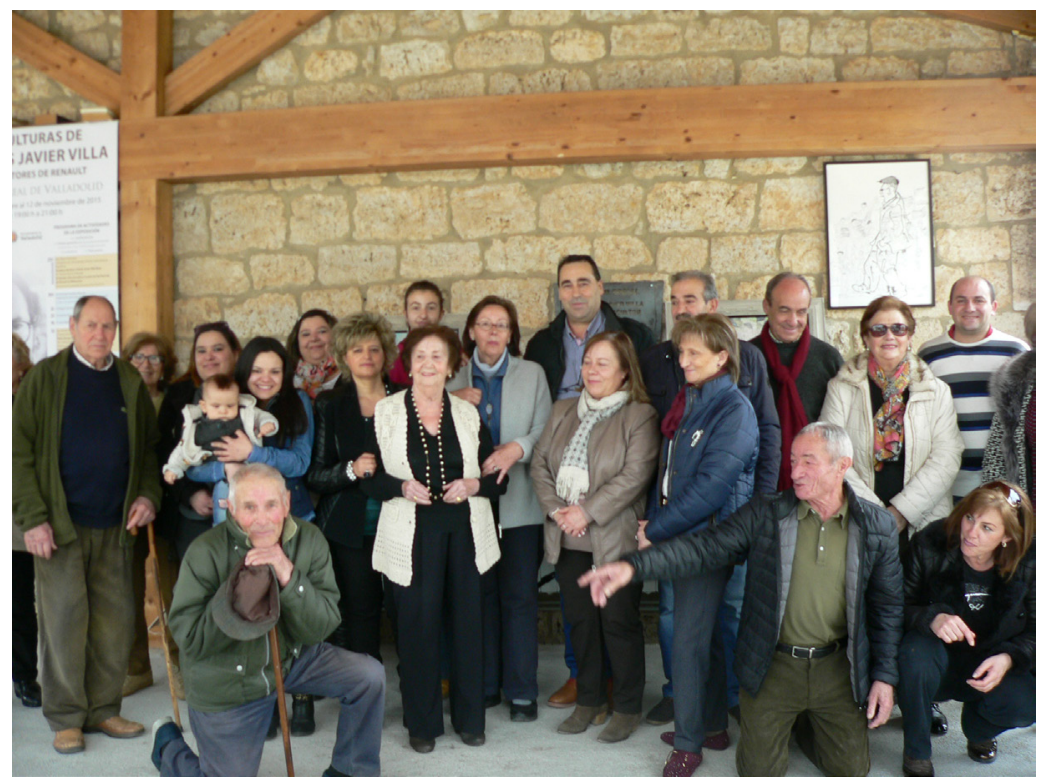

\section{Enlace Renault y la comunidad innovadora}

Ante la porosa globalización que todo lo invade, es notorio que los bienes tangibles e intangibles, estancos o en renovación, se exponen a dominios culturales en los que las expresiones y estilos son variables, fluidos y en continuo proceso de cambio. Y si las combinaciones y sincretismos resultantes son, con frecuencia, reinvenciones de multiprácticas rurales y urbanas, asimismo los actores, implicados en diseñar iniciativas, proceden no sólo del propio pueblo, sino de otros lugares, ciudades o de cualquier parte del mundo, con distintas formaciones, profesiones y dedicaciones. Y si esta variabilidad pudiera parecer problemática en la protección de los propios bienes tangibles e intangibles, más bien ocurre lo contrario. Como señala la UNESCO ${ }^{13}$, estas conexiones son inspiradoras y amplifican la consciencia de la diversidad cultural, el dialogo intercultural y el respeto mutuo por las formas de vida de otras comunidades.

En el proyecto Villaldemiro Cultural, los participantes involucrados trascienden la comunidad local, y actúan en calidad de promotores, al modo de lideres ocasionales, y donantes solidarios de su tiempo, obras y bienes. El proyecto nace del impulso y acuerdo de un grupo de doctores de universidad, escultores, familiares y amigos con el Alcalde y los vecinos, que aportan conjuntamente ideas, entusiasmo y amistad para proponer actividades e implementarlas. Son nombres, entre vecinos, promotores y amigos, que han aceptado ser desvelados: Enrique

13 UNESCO, Intangible Heritage, 2003. Disponible en http://whww.unesco.org/culture/heritage/intangible/html_eng/index_en.shtml/. Consultado el 25/11/2018. 
Espinel, Facundo Castro, Mari Carmen Martínez, Carlos de la Fuente, Adolfo Revuelta, Petra Herrero, Paulino Mena, Isaac Rilova, M. a Jesús Buxó, Almudena Delgado, Atilano Igelmo, Arancha Meceroyes, Gaspar Diez, Elena Núñez, Enrique Rodríguez, Eugenia Serrano, Rosa Alegre, Juan José Ortega, Alfonso Zarzuela, Fernando Porres, Ángel Membiela, Soledad Santiago, M. a Antonia Castro, Lorenzo Duque, Mari Carmen Arija, Felipe Rodríguez López, Armando Arenillas, Marina García, José Manuel Sancho, Paco Diez, por mencionar unos pocos.

Históricamente, la primera reunión, que dio lugar y voz al grupo, se realiza en la Fabrica del Canal de Abarca, un encuentro donde se perfila el proyecto artístico de vincular una exposición de escultura metálica con el Grupo de Escultores de Renault. Esta exposición se realiza en el Palacio Real de Valladolid con el título "Esculturas de Andrés Javier Villa y escultores de Renault" 29 octubre-12 de noviembre, 2015. Estos escultores son: Feliciano Álvarez, Miguel Hernández, Lorenzo Duque, Juan Martínez del Río, Ángel Membiela, Paulino Mena, Pedro Monge, Adolfo Revuelta y Felipe Rodríguez. El relator del encuentro escribe ${ }^{14}$ :

"Estamos organizado una exposición de escultura de Andrés Villa que estará orlada por obras de escultores en los que se da la común característica de haber aprendido la técnica de soldadura en Renault como el maestro Julio González, inspirador de los trabajos de Villa a la que ellos han ańadido su creatividad dando como resultado sus obras de arte. Arte, lenguaje o poesía tridimensional, que no es otra cosa la escultura."

Sin duda mejor orlado imposible por converger los orígenes formativos del poeta-escultor con la trayectoria creativa de los escultores de Renault que supieron transferir sus habilidades en metalistería industrial a la escultura. No es baladí recordar que hasta finales del siglo XIX todavía persistía la idea que lo tecnológico ocupaba el lado oscuro de la creatividad por su cualidad manipuladora de la naturaleza de suerte que se tendía a encubrir como una presencia invasora y antiestética, por no decir malévola. Sin duda la industria automovilística y la arquitectura metálica fueron pioneros en asignar significación estética a sus realizaciones al compatibilizar la funcionalidad con el diseño de líneas armónicas y así suscitar el interés y la aceptabilidad públicos. Con el tiempo, objetos y construcciones adquieren valor estético y pasan a ser piezas museísticas, a la vez que los expertos en metalistería exploran artísticamente materiales y técnicas y experimentan con las tendencias canónicas y subversivas de la época. De entre los maestros del soplete, cabe señalar a Julio González (1876-1942) y a David Smith (1906-1965), que

14 E. Espinel, Correspondencia, Promotor y Secretario del Premio A. J. Villa Pérez de Escultura Metálica, 2015. 
habían trabajado respectivamente en Renault, Paris, y en Studebaker, South Bend, Indiana, y poseían el conocimiento de la herrería y la metalistería en su profesión artesana e industrial. Adhiriéndose al nomadismo estilístico del arte del siglo XX, pasan a usar el soplete para dibujar-recortar, perforar y soldar- el metal y así crear un espacio escultórico donde hacer notar la sensibilidad expresiva del metal en las suturas del fundido, las superficies toscas y los fragmentos irregulares. De ahí el enlace artístico entre los escultores de Renault y A. J. Villa quien sigue esta tradición escultórica por la influencia que recibe del profesor Rob Licht al matricularse en cursos que impartía de escultura metálica en el Ithaca College y Adult Education en Cornell University, a finales de los años 90, durante una larga estancia en Estados Unidos.

A la exposición en el Palacio Real, y a los diferentes actos, proyecciones, conferencias y debates asistieron los vecinos de Villaldemiro así como los intelectuales, escultores, críticos y amigos del proyecto Villaldemiro Cultural. Estos encuentros culminan con el acuerdo para enunciar y firmar la Declaración de Valladolid a favor de la Escultura Metálica el 12 de noviembre de 2015. Sus fines son

\section{ESCULTURAS DE ANDRÉS JAVIER VILLA Y ESCULTORES DE RENAULT}

\author{
Palacio Real de Valladolid
}

Del 29 de octubre al 12 de noviembre de 2015 De 19:00 h a 21:00 h
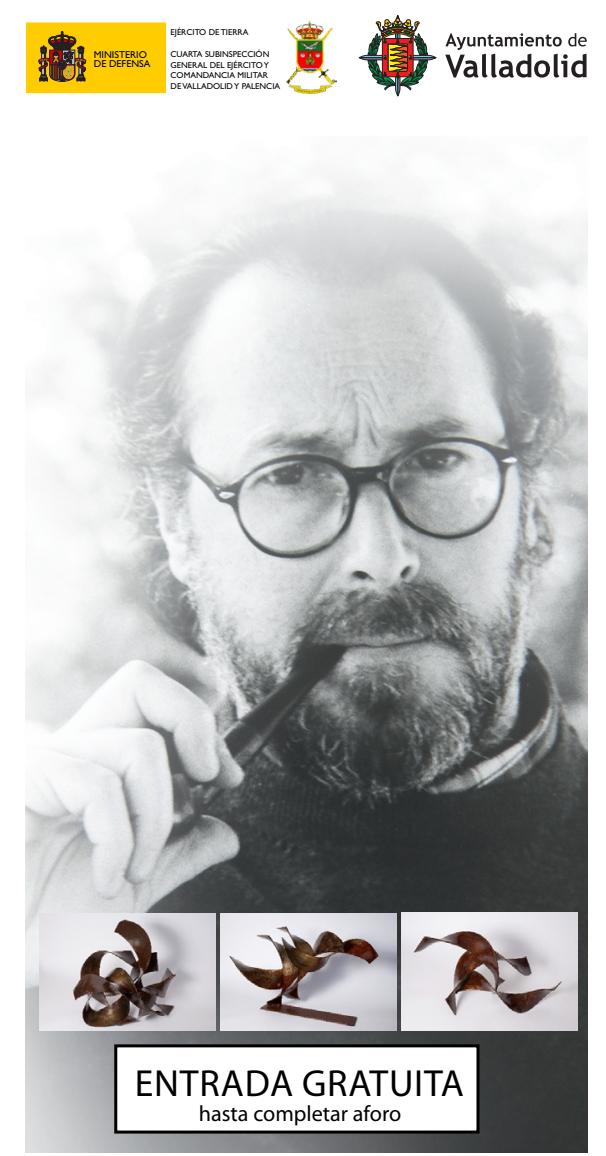
apoyar la especificidad de las técnicas de soldadura metálica para la creación artística, estimular estos aprendizajes en las Escuelas y Centros de Bellas Artes y animar a los museos y salas de exposiciones a mostrar estas obras así como promover su difusión en los medios de comunicación.

A partir de aquí se promueven nuevas formulas y actividades para distinguir y patrocinar la escultura metálica. Se instituye el Día del Escultor de Castilla y León a celebrar anualmente el segundo domingo de noviembre en Villaldemiro, 
y con este motivo se crea el Premio de Escultura Metálica "Andrés Javier Villa Pérez”. En 2016, este premio se otorga al eminente escultor P. Alfonso Salas O.P. del Monasterio de Caleruega y, en 2017, ya premio internacional, a la distinguida escultora mexicana Miriam Pérez. En su tercera edición, 2018, el galardonado va a ser el reconocido escultor Martín Chirino. Se organizan también "Encuentros de Escultura en Primavera" con otra institución -Foro de la Lengua y Cultura Francesa- y donante Rubí5-. Y, en la segunda edición, abril 2018, se consolida un premio de "Reconocimiento al Escultor Distinguido" que se concede al eminente escultor Venancio Blanco, ya fallecido. Esta vez el acto y las conferencias se realizan en el Monasterio de Caleruega, y, una vez presentada la biografía artística del escultor y entregado el premio, se organizan varias sesiones en las que los propios escultores invitados exponen las características de sus obras. Al final, el alcalde de Villaldemiro, Facundo Castro del Cerro, inaugura la web villaldemirocultural.org y presenta su diseño y contenido.

Situar a Villaldemiro en red permite visualizar estos encuentros y actividades, participantes y fechas que se vienen celebrando desde el 2015 bajo la rúbrica Villaldemiro Cultural, tanto en el pueblo como en otros contextos. Esta web se organiza en diferentes unidades temáticas que corresponden a una infobásica del pueblo, la historia, la denominación "villa de la escultura metálica", el museo virtual de escultura metálica, así como las donaciones y la biblioteca. El museo virtual esta diseńado para crear un espacio en red, de acceso abierto, donde visualizar obras escultóricas e impulsar una atmósfera expositiva que sirva a estudiosos y amantes del arte sin restricciones horarias, desplazamientos y gastos, así como conectarse en red con otros museos nacionales y extranjeros. De momento se expone el fondo propio con la obra de A. J. Villa y se programa para exhibir obras de los premiados y de nuevos donantes mediante la cesión de imagen. En definitiva, esta diseñada para inspirar un espacio ciber donde fortalecer el ejercicio de la escultura metálica y la exposición digital-experimental de artistas que quieran colaborar y desarrollar nuevas actividades inmersivas en el futuro.

\section{Solidaridad cultural y donaciones}

En el ámbito de la innovación no hay que confundir el impulso de hacer, con la fuerza para moverse, algo así como pasar de hablar a escribir, ni tampoco con la impresión de novedad que sería propia del multiculturalismo globalizado, el consumo cultural del etnoturismo o cualquier comercialización de la diversidad étnica. Más bien se asienta en la metaculturalidad en cuanto a generar cultura de culturas por la circulación abierta de bienes materiales e inmateriales y activar un sentido de la identidad más plural acorde al despliegue y exposición de valores, actitudes y gustos estéticos en los medios de comunicación y la red. Y, entre los fines de la innovación no sólo se busca incrementar la eficacia tecnológica, económica y el bienestar social, sino posicionar, a modo de gobernanza participativa, las 


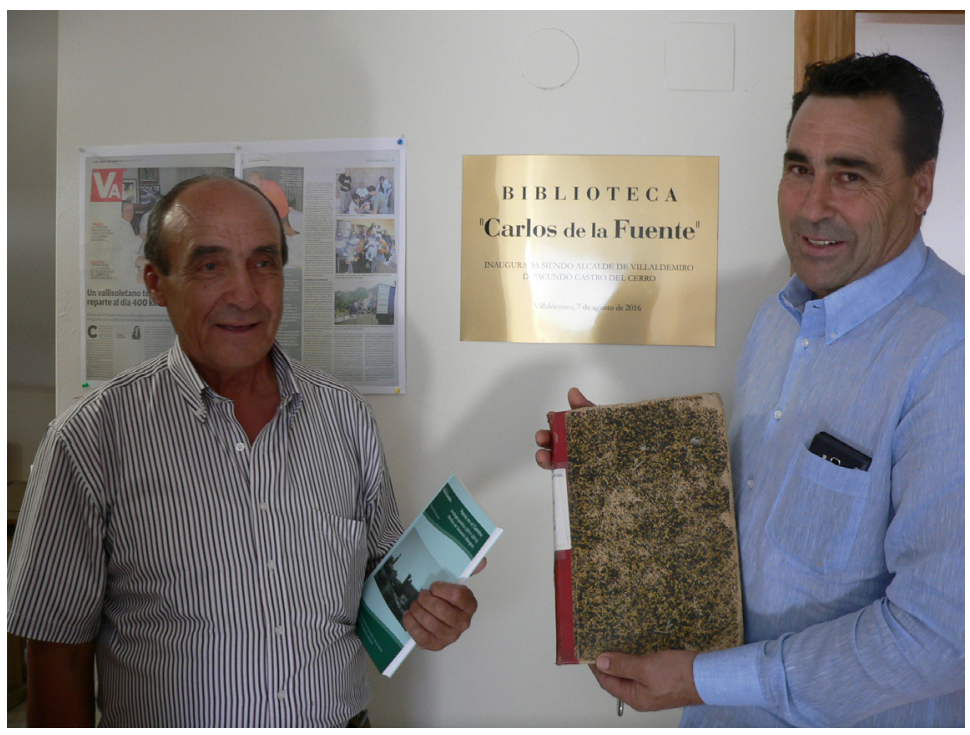

propuestas y decisiones de los agentes sociales -grupos de interés, comunidades, etc.-, ya que rara vez acceden a las agendas cerradas/atascadas de los Directorios patrimoniales en las instituciones comunitarias, los museos y las fundaciones de mecenazgo.

En este sentido, la acción de innovar aporta reflexividad social al reconocer que la defensa de lo propio no puede existir fuera de la interacción y el desarrollo con otros sistemas ecológicos, culturales e institucionales. Y también entender que la eficacia y la participación no se activan si no es con la apoyatura de la solidaridad implícita en la cultura cívica. No se trata del impulso solidario de la proclama y el entusiasmo circunstancial sino de la aportación de ideas para implantar una comunidad creativa a la vez que refinar el voluntarismo hacia la participación responsable. Una solidaridad cívica que, más que seguir principios, implica vivirlos en espacios de dialogo, colaboración y donación, entre pueblos, ciudades, a nivel nacional e internacional. En un mundo globalizado, como bien señala Carloni ${ }^{15}$, se trata de aplicar una solidaridad holística, esto es, una visión integral de la vida en común sobre la base de la educación, la cooperación y la solidaridad. Así, pues, aunar la apoyatura solidaria con los proyectos de conservar e innovar objetos, arquitecturas y bienes intangibles aboga siempre a favor del refinamiento ético y estético de la humanidad y constituye una ofrenda a las futuras generaciones.

El proyecto Villaldemiro Cultural representa un caso de solidaridad cultural, una apuesta que reúne diferentes voluntades a favor de crear un lugar de

15 A. Carloni, "La solidaridad, la educación y los medios desde la Antropología”, en Comunicar, 15 (2000), pp. 61-66. 
encuentro ético y estético, esto es, constituir una comunidad creativa con el fin de armonizar los bienes tangibles e intangibles del pueblo con nuevos recursos, formatos y experiencias culturales en sintonía con la complejidad transcultural de hoy. Activar la solidaridad en tiempo, ideas y donaciones requiere protagonistas que aporten criterio y sensibilidad y la capacidad de mantener el impulso inicial que mueve a la acción, en este caso, la colaboración del alcalde y los vecinos y las iniciativas de los promotores y amigos del proyecto en un intercambio continuado de ideas, trabajos de acondicionamiento, actividades, libros y obras escultóricas, entre otras muchas cosas.

Siendo Villa de la Escultura Metálica, la mayor parte de las donaciones pertenecen a este ámbito artístico, sin obviar pinturas y grabados en menor cuantía. De la obra de A. J. Villa se dona gran parte de la misma y el Ayuntamiento también recibe obras de los escultores de Renault, Revuelta, Membiela, Mena y Monge, así como de los que han recibido el premio de escultura, el Padre Salas y Miriam Pérez. Hasta ahora expuestas en la Alcaldía, a partir de la inauguración del museo van a constituir el fondo expositivo y formar parte de las instalaciones eventuales al aire libre en plazas, esquinas y rincones deleitables del pueblo.

En esta activación de la vida cultural de Villaldemiro, además, hay que destacar la donación de libros hasta el punto que el 7 de agosto de 2016 se inaugura una biblioteca con el nombre del principal donante, Carlos de la Fuente, Premio Nacional de Solidaridad del Ministerio de Trabajo. Bajo el lema "Más libros, más libres", la biblioteca abre con cerca de 5.000 volúmenes, número que se ha ido ampliando con nuevas donaciones hasta

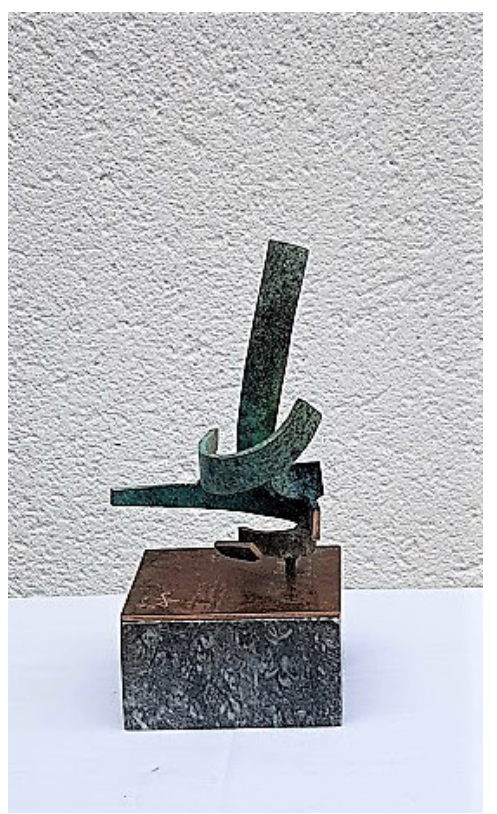
la actualidad.

De ahí que la comunidad cultural de Villaldemiro haya instituido un Premio anual a la Solidaridad Cultural otorgado a los principales impulsores: en 2015 a Enrique Espinel, secretario del Premio de Escultura, y Mari Carmen Martínez. En 2016 al escultor Adolfo Revuelta y Petra Herrero quienes hacen donación de la obra escultórica titulada "Llama”, escultura que, a partir de 2017, se consolida como el galardón del Premio Andrés Villa Pérez de Escultura Metálica. Y el tercer premio a la Solidaridad Cultural lo reciben Elena Núnez y el historiador Isaac Rilova por elaborar el texto sobre la Historia de Villaldemiro para la web villaldemirocultural. 
Cabe concluir que la solidaridad reflexiva ayuda a transvalorar ${ }^{16} \mathrm{o}$ aprender a verse una vez se ha puesto la mirada en el Otro, paso previo para implicarse responsablemente en el intercambio cultural y la hibridización, esto es, relacionarse e influirse culturalmente entre sí evitando la apropiación de bienes no consentida e irregular. Ambos criterios permiten subsanar el código cerrado o canónico de los sistemas culturales y entender la vida social como una práctica negociada transculturalmente entre agentes que, al así hacerlo, mejoran sus repertorios interpersonales y adquieren un sentido más universal, transvaloral e incluso irónico de la realidad cultural.

En el proceso globalizador y multiplicador de estilos de vida posibles, las comunidades se activan al apreciar que hay más espacio y otros tiempos fuera del pueblo y que la capacidad comparativa permite rearticular diferencias y enfrentarse a nuevos a retos y problemas. Aplicado al patrimonio tangible e intangible, unir las iniciativas privadas y de la comunidad en proyectos de preservación de la herencia del pasado constituye hoy, simultáneamente, un compromiso que implica el diseño y la gestión de futuros culturales, siendo clave la inteligencia social pues los modelos, formatos y significados culturales, resultado de la renovación, innovación e improvisación, son reales en sus consecuencias.

Reconocer, en definitiva, y apoyar la idea que la herencia cultural no es sólo un legado del pasado, sino que nos ayuda a forjar el camino a seguir y diseñar nuestro futuro. Como comunidad creativa, Villaldemiro Cultural se suma al mensaje de la Comunidad Europea "Heritage, where the past meets the future", y así celebra el Año del Patrimonio Cultural, 2018.

16 T. Todorov, Cruce de culturas y mestizaje cultural. Madrid: Ediciones Júcar, 2005. 
